\title{
Performance patterns in Conners' CPT among children with attention deficit hyperactivity disorder and dyslexia
}

\author{
Padrão de desempenho no Conners' CPT em crianças com transtorno do déficit de \\ atenção e hiperatividade e dislexia \\ Monica Carolina Miranda', Thais Barbosa², Mauro Muszkat ${ }^{3}$, Camila Cruz Rodrigues ${ }^{4}$, Elaine Girão Sinnes ${ }^{5}$, \\ Luzia Flavia S Coelho ${ }^{6}$, Sueli Rizzuti7, Sonia Maria Mota Palma ${ }^{8}$, Orlando Francisco Amodeo Bueno ${ }^{9}$
}

\begin{abstract}
This study investigated the performance of children with attention deficit hyperactivity disorder (ADHD) and dyslexia using Conners' Continuous Performance Test (CCPT). The clinical groups were composed of 52 children with ADHD and 32 children with dyslexia. Performance in the CCPT was evaluated using ANCOVA to compare the clinical groups with the normative Brazilian sample. The ADHD group performed worse than the normative sample in almost all of the measurements, except for reaction time and response style. The dyslexia group scored higher on commissions, variability, perseverations and inconsistency in the reaction time over the six time blocks (Hit SE Block Change) than the children in the normative Brazilian sample. The ADHD and dyslexia groups differed in omission measurements, Hit RT SE, variability, perseverations, Hit RT Interstimulus Intervals (ISI) Change and Hit SE ISI Change. We thus found that the dyslexia group had specific deficit patterns, with greater response to non-target stimuli, greater perseveration and response variability, and difficulties in hit reaction time as the test progressed.
\end{abstract}

Key words: Conners' Continuous Performance Test, child development, attention deficit/hyperactivity disorder, learning disorders, dyslexia.

\section{RESUMO}

O presente estudo investigou o desempenho de crianças com transtorno do déficit de atenção e hiperatividade (TDAH) e dislexia no Teste de Desempenho Contínuo de Conner (do inglês Conners' Continnuous Performance Test). Foram considerados dois grupos clínicos: 52 crianças com TDAH e 32 com dislexia. O desempenho no CCPT foi analisado por meio do teste ANCOVA, comparando os grupos clínicos com a amostra de normatização brasileira. 0 grupo TDAH teve pior desempenho que os controles em quase todas as medidas, exceto em medidas de tempo de reação e estilo de resposta. Já o grupo dislexia teve maiores escores em comissões, variabilidade, perseverações e inconsistência nas mudanças de tempo de reação no decorrer dos seis blocos de tempo (Hit SE Block Change). Os grupos TDAH e disléxicos diferiram entre si nas medidas de omissões, variabilidade do tempo de reação, perseverações, mudança de tempo de reação por intervalos interstimulus. Verificou-se assim que as crianças com dislexia apresentam padrões específicos de déficits, com maior resposta aos estímulos não alvos, maior perseveração e variabilidade de respostas, assim como dificuldades no tempo de reação conforme o desenvolvimento do teste.

Palavras-Chave: Teste de Desempenho Contínuo de Conner, desenvolvimento infantil, transtorno do déficit de atenção e hiperatividade, transtornos de aprendizagem, dislexia.

\footnotetext{
1PhD, Coordinator of the Child Neuropsychological Care Group, São Paulo Neuropsychology Center/AFIP, and Supervisor at the São Paulo Medical School, Federal University of São Paulo (UNIFESP), São Paulo SP, Brazil;

${ }^{2} \mathrm{MSc}$, Doctoral student in the Department of Psychobiology, São Paulo Medical School, UNIFESP, São Paulo SP, Brazil;

${ }^{3}$ PhD, Coordinator of the Child Neuropsychological Care Group, São Paulo Neuropsychology Center/AFIP, and Supervisor at the São Paulo Medical School, UNIFESP, São Paulo SP, Brazil;

${ }^{4}$ PhD, Collaborator at the Child Neuropsychological Care Group, São Paulo Neuropsychology Center/AFIP, São Paulo SP, Brazil;

${ }^{5}$ Psychologist, Collaborator at the Child Neuropsychological Care Group, São Paulo Neuropsychology Center/AFIP, São Paulo SP, Brazil;

${ }^{6} \mathrm{MSc}$, Collaborator at the Child Neuropsychological Care Group, São Paulo Neuropsychology Center /AFIP, São Paulo SP, Brazil;

${ }^{7}$ PhD, Physician in the Child Neuropsychological Care Group, São Paulo Neuropsychology Center/AFIP, São Paulo SP, Brazil;

${ }^{8}$ Doctoral student in the Department of Psychobiology, São Paulo Medical School, UNIFESP, São Paulo SP, Brazil;

${ }^{9}$ Full Professor in the Department of Psychobiology, São Paulo Medical School, UNIFESP, São Paulo SP, Brazil.

Correspondence: Mônica Carolina Miranda; Departamento de Psicobiologia, Universidade Federal de São Paulo (UNIFESP); Rua Embaú 54; $04039-060$ São Paulo SP - Brasil; E-mail:mirandambr@yahoo.com.br, monica@cpnsp.com.br

Support: Associação Fundo de Incentivo à Pesquisa - AFIP.

Conflict of interest: There is no conflict of interest to declare.

Received 24 February 2011; Received in final form 01 November 2011; Accepted 09 November 2011
} 
Rather than a unitary construct, attention is a complex process that relates to a range of components, such as initiation or focusing, shifting attention and sustaining attention or vigilance. It has been argued that sustained attention is the most significant deficit in a number of disorders. The Continuous Performance Test (CPT) is a test with well-recognized and reliable measurements, and is often used to obtain quantitative information regarding an individual's ability to sustain attention over time $\mathrm{e}^{1-3}$.

The commercial version of the CPT that is widely used for research and clinical practice, and often included in batteries for neurodevelopmental disorders, is Conners' Continuous Performance Test II (Conners' CPT; CCPT) ${ }^{4}$, which differs from other versions. In addition to the reaction time and omission and commission errors, Conners' CPT also includes changes in the reaction time for different interstimulus intervals (ISIs) and measurements based on signal detection theory. Signal detection theory is applied as a measurement to distinguish between several determinants of the subjects' performance in a vigilance task. In any sustained attention task, the fundamental question is to determine whether there is attention impairment due to a loss of perceptual sensitivity to detect the signal or due to changes in the response decision criteria $^{5-7}$.

Consequently, Conners' CPT provides 15 measurements that potentially reflect different dimensions of attention. Furthermore, few studies applying Conners' CPT have used the full potential of the test to analyze several dimensions of attention ${ }^{8,9}$.

Studies have shown that the CPT paradigm consistently distinguishes control groups from those with attention deficit hyperactivity disorder (ADHD) through classical indices ${ }^{1,6}$. A meta-analysis by Losier et al. ${ }^{10}$ examined 26 studies on ADHD children. Although different CPT versions were used, the studies consistently showed that ADHD children made significantly more omission and commission errors than normal children.

Concerning Conners' CPT, meta-analysis studies have shown the importance of CCPT measurements in detecting clinical cases of ADHD. Epstein et al. ${ }^{6}$ found that children with $\mathrm{ADHD}$ had greater variation in their reaction times and made more omission and commission errors (as demonstrated in other versions), but they had lower detectability (d') scores. This suggested that they had more difficulty in distinguishing target from non-target stimuli. It was also found that the CCPT parameters revealed relationships among multiple ADHD symptom domains.

Furthermore, it has not yet been established in the literature whether attention difficulties are a feature of developmental dyslexia. Previous studies have reported attention deficits in dyslexia subjects during some tasks, using both visual $^{11}$ and auditory ${ }^{12}$ methods, and with or without accompanying ADHD. However, very few studies have used the
CPT paradigm to assess children with learning disabilities ${ }^{7,13}$, while only a few have specifically studied dyslexic children who also presented attention deficits ${ }^{14,15}$.

Taroyan et al. ${ }^{15}$ compared dyslexic children and controls using a modified version of the classical CPT. There were neither significant differences nor consistent intergroup trends in the behavioral indices for CPT performance between the control and dyslexic groups.

Kupietz ${ }^{14}$ administered the (modified) CPT to three groups of children: control, learning-disabled (LD), and LD with an ADHD diagnosis. Correct detection and commission errors were analyzed, but these measurements were not different across the diagnostic groups.

According to these studies, abnormal attention performance is not a 'core' feature of developmental dyslexia. However, Swanson ${ }^{13}$ found differences between LD and nonLD children using the CPT-AX version. They analyzed four measurements and found that the LD group exhibited less consistent responses, more false alarms, lower $d$ ' and more conservatism $(\beta)$ than the non-LD children.

The only study using Conners' $\mathrm{CPT}^{7}$ failed to distinguish ADHD and LD subjects from clinical controls, but only when using the overall index. Thus, this measurement alone is not sensitive to developmental changes and does not differentiate among distinct disabilities.

Consequently, there is controversy in the literature regarding the characteristics of the attention measurements presented by LD children. According to $\mathrm{McGee}^{7}$, "although much research has identified measures that discriminate children with $\mathrm{RD}$ and $\mathrm{ADHD}$ from normal controls [...] few studies have found instruments that reliably distinguish them from each other."

Thus, the aim of the present study was to investigate the performance parameters of children with dyslexia, children with attention deficit/hyperactivity disorder (ADHD) and control children using Conners' Continuous Performance Test.

\section{METHODS}

\section{Sample}

The clinical groups were composed of 52 children with $\mathrm{ADHD}$ and 32 children with dyslexia, and the CCPT protocols came from subjects successively referred for neuropsychological assessment from two outpatient clinics of the Interdisciplinary Child Neuropsychological Care Group (Núcleo de Atendimento Neuropsicológico Infantil Interdisciplinar; NANI) of the Federal University of São Paulo between 2006 and 2008.

Information regarding evaluation procedures and classifications according to the DSM-IV was collected retrospectively from each patient's medical file. The neuropsychological evaluation procedures used in both outpatient clinics and 
the exclusion criteria that were relevant for each diagnostic group were as follows:

1) $\mathrm{ADHD}$ group: Children were included if they met the inclusion criteria according to the DSM-IV and EACIP scale criteria ${ }^{16}$. The children were referred for a multidisciplinary assessment schedule that consisted of medical and neuropsychological evaluation, as well as social and family assessment.

The neuropsychological evaluation included an examination of the subject's intellectual level using: the Wechsler Intelligence Scale for Children (WISC-III), abbreviated version (estimated IQ); a computerized attention test using Conners' Continuous Performance Test (CCPT); Digit Span and Corsi Block tests to assess working memory; and the Rey-Osterrieth Complex Figure Test, which assesses visual constructive functions and visual memory (Rey Memory).

According to the DSM IV criteria for ADHD, 26 subjects (50\%) met the criteria for hyperactivity and inattention, 13 (25\%) were predominantly inattentive and 13 (25\%) had hyperactivity/impulsivity.

2) Dyslexia group: The diagnosis was established according to the subject's performance in the following assessments:

Oral language - semantic factors (ABFW Vocabulary Test; naming), syntactic factors (sentence completion), phonological factors (test of phonemic discrimination and phonological awareness; CONFIAS) and sentence comprehension.

Reading abilities - single-letter reading, low and high frequency words and pseudowords, speed and reading comprehension during silent and out loud reading.

Writing abilities - single-letter writing, low and high frequency words and pseudowords.

Literacy assessment - writing, reading and mathematics tasks, the School Performance Test $(\mathrm{SPT})^{17}$, reading and writing letters, words and pseudowords, and the reading and comprehension of texts. The children were classified as dyslexic in accordance with the DSM-IV criteria, their scores in the SPT and their abilities to read and comprehend texts.

Cognitive ability was evaluated using: the Wechsler Intelligence Scale for Children, full version (WISC-III); Digit Span and Corsi Block tests for working memory assessment; the Rey Complex Figure Test; semantic memory assessed by the "animals and fruits" category test (semantic fluency); and the Wisconsin Card Sorting Test.

Subjects with intellectual disabilities $(\mathrm{IQ}<70)^{18}$, personality disorders and neurological deficits, such as brain lesions, epilepsy and vascular injuries, were excluded from both groups. Children with symptoms of inattention, hyperactivity and learning difficulties secondary to other diagnoses were excluded from the ADHD group.

All of the procedures in the present study were approved by the Research Ethics Committee of the institution to which the researchers belong (Federal University of São Paulo - UNIFESP).

\section{Procedures}

The version that we used was Conners' Continuous Performance Test, in the form of computer software for Windows (CCPT4), and it was presented on a laptop. The total application time was around 25 minutes, which included both the training and the test itself. The children were instructed to press the space bar on the keyboard for any letter displayed on the screen except ' $X$ '. Each letter was presented for approximately 250 milliseconds. There were 324 target stimuli (non-X letters) and 36 non-target stimuli (Xs). Six blocks of stimuli were presented, each with 3 sub-blocks of 20 trials (letter presentations), and one for each interstimulus interval of 1, 2 and 4 seconds. The order in which the different ISIs were presented varied across the blocks.

\section{Statistical analysis}

To analyze the differences between the groups in relation to the gender variable, the chi-square test was used. To analyze the age variable in each group, ANOVA was applied.

Because the mean age systematically differed according to the group conditions and the performance in the CCPT is influenced by this variable ${ }^{3,4}$, analysis of covariance (ANCOVA) was conducted. Age was covaried to control for the possible confounding of this variable with the main effects of the group.

All of the CCPT measurements were converted into $t$ scores and percentiles by means of the software program. However, we compared the value scores of each variable, because $t$-scores are transformed values in relation to the normative data obtained in the USA, and our previous study demonstrated that Brazilian children ${ }^{3}$ have CCPT scores differing from those of children in the USA.

The magnitudes of the effects were determined through size calculations (Cohen $d$ ). The statistical software used was SPSS version 11.0 and SAS proc. GLM version 8.01. The significance level was 0.05 .

\section{RESULTS}

Table 1 shows the age and gender distributions of the samples for each group in the present study. The numbers of male and female subjects were different across the clinical groups ( $\mathrm{p}=0.000003$ ). The ADHD group was composed of 43 boys, and the dyslexia group had 22 boys. There were significant differences in the mean age: $7.9(\mathrm{SD} \pm 2.1)$ years in the $\mathrm{ADHD}$ group; $10.3(\mathrm{SD} \pm 1.7)$ years in the dyslexia group; 8.1 $(\mathrm{SD} \pm 2.1)$ years in the control group.

After assessing overall cognitive performance, an average IQ of 100 (ranging from 80 to 126) was found in the ADHD 
group, and an average IQ of 99 (ranging from 83 to 115) was found in the dyslexia group. There were no significant differences between the clinical groups.

Table 2 shows the CCPT performance for each group. The ANCOVA results showed significant differences between the ADHD group and the Brazilian standardization sample. ADHD subjects performed worse controls in all of the test measurements $\left(p_{s}<0.00002\right)$, except for the Hit RT, Response Style, Hit RT Block Change and Hit SE Block Change $(p<0.46)$ ( $\mathrm{SE}$ = standard error; $\mathrm{RT}$ = reaction time).

The dyslexia group exhibited higher percentages of commissions, variability and perseverations, and a higher Hit SE Block Change than the children in the Brazilian standardization sample $\left(\mathrm{p}_{\mathrm{s}}<0.00002\right)$.

We found differences in the percentage of omissions, the Hit RT SE, variability, perseverations, the Hit RT ISI Change and the Hit SE ISI Change $\left(\mathrm{p}_{\mathrm{s}}<0.00002\right)$ when comparing the ADHD and dyslexia groups. The ADHD group displayed poorer performance.

The effect sizes, as calculated by the Cohen $d$ for all of the significant effects, had large magnitudes (Table 3).

Table 1. Age and gender distribution in each group.

\begin{tabular}{|c|c|c|c|}
\hline Group & $\mathrm{n}$ & Gender & Mean age (SD) \\
\hline ADHD & 52 & $\begin{array}{l}\text { Male } 43(82.7 \%) \\
\text { Female } 9(17.3 \%)\end{array}$ & $7.9(2.1)$ \\
\hline LD & 32 & $\begin{array}{c}\text { Male } 22(68.8 \%) \\
\text { Female } 10 \\
(31.2 \%)\end{array}$ & $10.3(1.7)$ \\
\hline Controls & 475 & $\begin{array}{c}\text { Male } 236(49.7 \%) \\
\text { Female } 239 \\
(50.3 \%)\end{array}$ & $8.1(2.1)$ \\
\hline
\end{tabular}

ADHD: Attention deficit hyperactivity disorder; LD: Learning disabilities.

\section{DISCUSSION}

Children with ADHD had poor performance in 10 out of the 15 measurements. This group made more omission and commission errors, had more variable RTs, had more perseveration responses and was less able to discriminate target from non-target stimuli $\left(d^{\prime}\right)$. There were no differences in the reaction time and $b$ index compared with controls, thus confirming other studies that used this test version ${ }^{6}$.

With regard to the differences in the omission and commission errors, the standard error of the reaction time in our

Table 3. Effect size (Cohen d) measurements for all of the groups.

\begin{tabular}{lccc}
$\begin{array}{l}\text { CCPT } \\
\text { measurements }\end{array}$ & $\begin{array}{c}\text { Cohen d } \\
\text { ADHD versus } \\
\text { LD group }\end{array}$ & $\begin{array}{c}\text { Cohen d } \\
\text { ADHD versus } \\
\text { control group }\end{array}$ & $\begin{array}{c}\text { Cohen d } \\
\text { LD versus } \\
\text { control group }\end{array}$ \\
\hline \#Omissions & 0.7 & 1.0 & 0.4 \\
\%Omissions & 0.8 & 0.8 & 0.1 \\
\#Commissions & 0.2 & 0.6 & 0.3 \\
\%Commissions & 0.4 & 1.0 & 0.5 \\
Hit RT & 0.8 & 0.1 & -0.7 \\
Hit RT SE & 1.1 & 0.9 & -0.06 \\
Variability & 0.8 & 1.2 & 0.4 \\
Detectability (d') & -0.3 & -0.8 & -0.4 \\
Response Style (b) & -0.3 & -0.2 & 0.05 \\
Perseverations & 0.4 & 1.1 & 0.4 \\
Hit RT Block & 0 & 0.3 & 0.3 \\
Change & & 0.2 & 0.5 \\
Hit SE Block & -0.2 & 0.8 & 0.1 \\
Change & & 0.9 & 0.1 \\
Hit RT ISI Change & 0.8 & & \\
Hit SE ISI Change & 0.5 & &
\end{tabular}

CCPT: Conners' Continuous Performance Test; ADHD: Attention deficit hyperactivity disorder; LD: Learning disabilities; Hit RT: Hit Reaction Time; Hit RT SE: Hit Reaction Time Standard Error.

Table 2. Means and standard deviations of CCPT measurements for each group.

\begin{tabular}{|c|c|c|c|c|}
\hline CCPT measures & ADHD group & LD group & Control group & $\mathrm{p}$ \\
\hline \#Omissions & $35.1(27.5) * \#$ & $18.4(12.8)$ & $13.2(13.4)$ & $p=0.00002$ \\
\hline$\%$ Omissions & $10.9(8.5) * \#$ & $5.7(4.0)$ & $5.0(5.4)$ & $p=0.00002$ \\
\hline \#Commissions & $22.6(7.7)^{\star}$ & $20.6(8.2)$ & $17.4(8.6)$ & $p=0.0018$ \\
\hline \%Commissions & $66.9(19.2)^{*}$ & $57.2(22.8) *$ & $45.4(22.3)$ & $p_{s}<0.009$ \\
\hline Hit RT & $572.0(140.6)$ & $471.7(87.0)$ & $554.6(133.9)$ & $p=0.294$ \\
\hline Hit RT SE & $22.9(11.9) * \#$ & $12.7(5.4)$ & $13.2(8.9)$ & $p_{s}=0.00002$ \\
\hline Variability & $43.2(24.4) * \#$ & $26.1(18.3)^{\star}$ & $18.9(13.3)$ & $p_{s}<0.01$ \\
\hline Detectability (d') & $0.3(0.3)^{*}$ & $0.4(0.4)$ & $0.6(0.4)$ & $p=0.0002$ \\
\hline Response Style (b) & $1.0(0.5)$ & $1.4(1.7)$ & $1.3(1.8)$ & $p=0.46$ \\
\hline Perseverations & $18.6(19.2)^{\star} \#$ & $10.3(21.0)$ * & $2.9(3.5)$ & $p_{s}<0.00002$ \\
\hline Hit RT Block Change & $0.02(0.05)$ & $0.02(0.05)$ & $0.00(0.05)$ & $p=0.06$ \\
\hline Hit SE Block Change & $0.08(0.12)$ & $0.11(0.12)^{\star}$ & $0.05(0.10)$ & $p=0.004$ \\
\hline Hit RT ISI Change & $0.13(0.10) \star \#$ & $0.06(0.06)$ & $0.05(0.09)$ & $p=0.0002$ \\
\hline Hit SE ISI Change & $0.20(0.17)^{\star} \#$ & $0.08(0.26)$ & $0.04(0.17)$ & $p=0.00002$ \\
\hline
\end{tabular}

CCPT: Conners' Continuous Performance Test; ADHD: Attention deficit hyperactivity disorder; LD: Learning disabilities; Hit RT: Hit Reaction Time; Hit RT SE: Hit Reaction Time Standard Error; Hit RT BC: Hit Reaction Time Block Change; Hit SE BC: Hit Standard Error Block Change; Hit RT ISI Change: Hit Reaction Time ISI Change; Hit SE ISI Change: Hit Standard Error ISI Change. * Differs from control; \# ADHD differs from LD. 
study is consistent with previous studies that used different CPT versions ${ }^{1,5,7,10}$ or Conners' $\mathrm{CPT}^{6}$. In particular, children with ADHD made more omission errors that could be consequences of attention impairment. An increase in the number of commission errors (responses to stimuli other than the target) was also observed, which may reflect poor inhibitory control $^{1}$. An inconsistent response rate (standard error of the reaction time) and a larger number of perseverations (anticipated responses) were also observed in this group, thus indicating a rise in impulsivity.

One particularly important feature of our work is that we analyzed measurements, such as the Hit RT ISI Change and the Hit RT Block Change, that were not covered by most of the other studies ${ }^{6,7,10}$. Our study found poorer Hit RT ISI Change and Hit SE ISI Change performance in the ADHD group. These measurements assess the subject's ability to adjust to longer interstimulus intervals. Corkum and Siegel ${ }^{5}$ and Egeland and Kovalik-Gran ${ }^{8}$ indicated the relevance of analyzing these measurements in studies on sustained attention in ADHD children using CCPT because "the tasks which appear to best differentiate ADHD and normal children are those which place a heavy demand on the child's attention resources, those in which the child

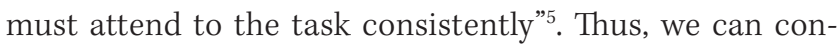
sider this to be a measurement of vigilance. In our study, $\mathrm{ADHD}$ children displayed slower reaction times as the time between the targets increased, and the reaction times became more erratic. This finding is an inconsistency in the response of ADHD children.

In summary, children with ADHD displayed specific deficits compared with the control group: failure of attention (omission error), failure of inhibitory control (commission error), inconsistency in the response rate (standard error of the reaction time), intra-participant variability, higher level of impulsiveness (perseverations) and poor vigilance (change in the interstimulus interval).

From our study, we concluded that CCPT may be a valuable research tool for helping to elucidate the true nature of the neuropsychological deficits associated with $\mathrm{ADHD}^{5}$. McGee et al. ${ }^{7}$ concluded that, despite its strengths, the usefulness of CCPT for the differential diagnosis of ADHD is questionable. However, our results and those of Epstein et al. ${ }^{6}$ show that the overall index alone is not sensitive to developmental changes, and all of the CCPT measurements must be analyzed in order to distinguish ADHD children, given the multifaceted nature of this disorder.

The children in the dyslexia group had elevated numbers of commission errors, variability, perseveration responses and inconsistency in the reaction time over the six time blocks (Hit SE block) in comparison with the control group. Thus, the children with LD had more errors due to failures in inhibitory control (commission errors), more variable responses, more anticipatory responses (perseverations) and less response consistency as the test progressed, in comparison with the control group.

Kupietz ${ }^{14}$, McGee et al. , and Taroyan et al. ${ }^{15}$ used different CPT versions and failed to find differences between the LD and control groups when analyzing their rates of correct detection, omission and commission errors, reaction times and overall indices. Swanson ${ }^{13}$ found differences in correct detection, false alarms and commissions that were similar to those in our study; unlike in our study, they also found differences in the $d$ ' and $\beta$ values. However, the CPT-AX version used in their study differed from Conners' CPT-II and, therefore, their results are not comparable with those in our present study.

Both our results and those of Swanson ${ }^{13}$ revealed more commission errors in dyslexic children. The assumption is that dyslexic children probably differ from normal children in terms of some of their internal decision-making processes, as found by Swanson ${ }^{13}$. However, analysis of this index combined with a high perseveration rate suggests that anticipatory responses occurred in dyslexic children.

The other measurements in which the dyslexic children differed from the controls were variability and the Hit SE Block Change, which were not analyzed in previous studies ${ }^{6,13}$. Both of these measurements assess response consistency. The first indicates the variability presented by the subjects in terms of their own overall standard error, and the second assesses changes in the reaction time standard errors as blocks, thus indicating that, as the test progresses, the participants lose their capacity to maintain their previous performance ${ }^{1}$. This result reveals difficulty in sustaining attention (i.e. impaired capacity to maintain attention during the task).

Thus, our results show that dyslexic children may have inhibitory control difficulties, impulsivity and poor sustained attention compared with children without neurodevelopmental disturbances ${ }^{19}$.

In comparing dyslexic and $\mathrm{ADHD}$ children, our study showed that the children with $\mathrm{ADHD}$ displayed greater attention deficits (higher omission errors), highly variable reaction times, frequent inattention (Hit RT SE and variability), a higher rate of anticipatory responses (perseverations) and less consistent reaction times with longer stimulus intervals, thus indicating slower processing speed and an inconsistent response style during the task.

Previous studies ${ }^{14}$ used another version of the Continuous Performance Test (CPT-AX) and failed to find significant differences between these groups, which may have been due to the small sample size. The groups were composed of $11 \mathrm{LD}$ children and 13 non-ADHD children; in contrast, our sample was composed of 32 children with dyslexia and 52 children with ADHD. McGee et al. ${ }^{7}$ also failed to find differences between the LD and ADHD groups using the overall index of Conners' CPT. In the present study, we found substantial differences in the groups' specific CPT measurements, but not 
in their overall scores. Therefore, we conclude that the analyses have to be more refined in order to research and differentially diagnose the sustained attention capacities of children with developmental disorders.

Finally, it is important to note that the differences that we found in this study are not due an age difference between the groups. The ADHD group was younger than the LD and control groups because age-group effects became evident after covarying the data.

Some limitations of this study need to be pointed out. These include the small numbers of subjects in the clinical groups, thus limiting the ability to establish possible differences between the ADHD subtypes and precluding analysis on psychiatric comorbidities and learning disabilities in the ADHD group or on comorbidities commonly associated with dyslexia. Further work needs to be carried out to investigate whether the performance in the CCPT indices is associated with these relevant aspects of the pathological condition.

Despite these limitations, our results confirm that Conners' CPT has considerable potential for measuring attention problems, can distinguish ADHD from dyslexia, can distinguish both of these from clinical controls ${ }^{7}$ and can be used as a diagnostic instrument for $\mathrm{ADHD}$ and $\mathrm{LD}^{20}$.

\section{References}

1. Riccio CA, Reynolds CR, Lowe P, MooreJJ. The continuous performance test: a window on the neural substrates for attention? Arch Clin Neuropsychol 2002;17:235-272.

2. Parasuraman R. The Attentive Brain. Cambridge: MIT Press; 1999.

3. Miranda MC, Sinnes EG, Pompéia S, Bueno OFA. A comparative study of performance in the Conners' Continuous Performance Test between Brazilian and North American children.J Atten Disord 2008;11:588-598.

4. Conners CK. Conners' continuous performance test. Toronto: MultiHealth System; 2002

5. Corkum PV, Siegel LS. Is the Continuous Performance Task a valuable research tool for use with children with Attention-Deficit-Hyperactivity Disorder? J Child Psychol Psychiatry 1993;34:1217-1239.

6. Epstein JN, ErkanliA, Conners CK, Klaric J, CostelloJE,Angold A. Relations between Continuous Performance Test performance measures and ADHD Behaviors.J Abnorm Child Psychol 2003;31:543-554.

7. McGee RA, Clark SE, Symons DK. Does the Conner's Continuous Performance Test aid in ADHD diagnosis? J Abnorm Child Psychol 2000;28:415-424.

8. Egeland J, Kovalik-Gran I. Measuring several aspects of attention in one test: the factor structure of Conners's continuous performance test. J Atten Disord 2010;13:339-346.

9. Egeland J, Kovalik-Gran I. Validity of the factor structure of Conners' CPT. J Atten Disord 2010;13:347-357.

10. Losier BJ, McGrath J, Klein RM. Error patterns on continuous performance test in non-medicated and medicated samples of children with and without ADHD: a meta-analytic review. J Child Psychol Psychiatry 1996;37:971-987.
11. Vidyasagar TR. Neural underpinnings of dyslexia as a disorder of visuo-spatial attention. Clin Exp Optom 2004;87:4-10.

12. Petkov Cl, O'Connor KN, Benmoshe G, Baynes K, Sutter ML. Auditory perceptual grouping and attention in dyslexia. Brain Res Cogn Brain Res 2005;24:343-354.

13. Swanson HL. A developmental study of vigilance in learning-disabled and nondisabled children. J Abnorm Child Psychol 1983;11:415-429.

14. Kupietz SS. Sustained attention in normal and in reading-disabled youngsters with and without ADDH. J Abnorm Child Psychol 1990;18:357-372.

15. Taroyan NA, Nicolson RI, Fawcett A.J. Behavioural and neurophysiological correlates of dyslexia in the continuous performance task. Clin Neurophysiol 2007;118:845-855.

16. Brito GN. The Conners Abbreviated Teacher Rating Scale: development of norms in Brazil. J Abnorm Child Psychol 1987;15:511-518.

17. Stein LM. Teste de desempenho escolar: TDE. São Paulo: Casa do Psicólogo; 1994

18. Simões, MR. Utilizações da WISC-III na avaliação neuropsicológica de crianças e adolescentes. Paidéia 2002;12:113-132.

19. Egeland J, Nordby, SJ, Ueland, T. Differentiating between ADHD subtypes on CCPT measures of sustained attention and vigilance. Scand J Psychol 2009;50:347-354.

20. Edwards MC, Gardner ES, Chelonis JJ, Schulz EG, Flake RA, Diaz PF. Estimates of the validity and utility of the Conners' Continuous Performance Test in the assessment of inattentive and/or hyperactive-impulsive behaviors in children.J Abnorm Child Psychol 2007;35:393-404. 